\title{
Desafios da cadeia da restauração florestal no Vale do Paraíba Paulista
}

\author{
Forest restoration chain challenges in the Paraíba Paulista Valley
}

\author{
Alexandra Andrade ${ }^{1}$ \\ Danúbia Caporusso Bargos ${ }^{2}$ \\ Tiaraju Mesquita Fialho ${ }^{3}$ \\ Sara Cristofaro ${ }^{4}$
}

\begin{abstract}
Resumo
O compromisso assumido pelo Brasil na Conferência das Nações Unidas sobre as Mudanças Climáticas de 2015 - COP 21, de restaurar 12 milhões de hectares de floresta em seu território ganhou destaque nos debates e atividades de todos os envolvidos na cadeia da restauração florestal no país. A discussão se dá, principalmente, em função do desconhecimento da capacidade de articulação e preparo do segmento em diferentes níveis para enfrentar o desafio da restauração florestal em larga escala. O principal objetivo deste trabalho foi realizar um diagnóstico preliminar da situação atual e dos principais desafios para a estruturação da cadeia de restauração florestal do Vale do Paraíba Paulista. Os resultados indicam a necessidade de uma maior e melhor articulação entre os segmentos da cadeia da restauração florestal da região, a fim de garantir a movimentação da economia local/regional, a viabilidade econômica e o cumprimento dos padrões técnicos e de adequação às normas e legislação vigentes no exercício das atividades ligadas a cadeia da restauração; Observa-se ainda que a região enfrenta grandes desafios, comuns a outras regiões do país, que vão desde o acesso às sementes florestais e áreas para restaurar até a dificuldade no acesso aos recursos financeiros existentes e a carência de conhecimento e capacitação técnica no exercício das atividades principalmente do grupo dos executores.
\end{abstract}

Palavras-chave: Restauração Florestal; Vale do Paraíba Paulista; Mercado Florestal.

\begin{abstract}
The Brazilian commitment to the United Nations Conference on Climate Change of 2015 - COP 21 to restore 12 million hectares of forest in its territory has been highlighted in debates and activities of all those involved in the forest restoration chain in Brazil. Mainly due to the lack of knowledge of the articulation and preparation of this segment at different levels to face the challenge of large-scale forest restoration. The main goal of this work is to carry out a preliminary diagnosis of the current situation
\end{abstract}

\footnotetext{
${ }^{1}$ Instituto Oikos de Agroecologia. Lorena. São Paulo. Brasil. E-mail: alexandraandrade19@gmail.com

2 Departamento de Ciencias Básicas e Ambientais. Escola de Engenharia de Lorena. Lorena. São Paulo. Brasil.danubiacbargos@usp.br

${ }^{3}$ Instituto Oikos de Agroecologia. Lorena. São Paulo. Brasil. tiarajufialho@gmail.com

483 Multimedia Consultoria. São Paulo. Brasil. sara.cristofaro@gmail.com

Artigo recebido em: 06/05/2018. Aceito para publicação em: 13/11/2018.
} 
in order to identify the challenges for structuring the forest restoration chain of the Vale do Paraíba Paulista. The results indicate that it is required a better and greater articulation among all segments of the forest restoration chain in the region in order to ensure the local / regional economic development, economic viability and implementation with technical standards and compliance with norms and legislation related to this network. It is also observed that the region faces major challenges, common to other parts of the country, ranging from access to forest seeds and areas to restore to the difficulty in accessing existing funding and the lack of technical knowledge and skills of the executor group mainly.

Keywords: Forest Restoration; Vale do Paraíba Paulista; Forest Market.

\section{Introdução}

Desde a década de 1980 as emissões de gases de efeito estufa por atividades antrópicas vem crescendo continuamente e têm sido apontadas por diversos pesquisadores como uma das principais causas das mudanças climáticas e despertado a preocupação pública e de governantes (SEEG, 2015). O estabelecimento do Comitê Intergovernamental de Negociação para a Convenção-Quadro sobre Mudança do Clima (INC/FCCC) impulsionou a discussão sobre diferentes formas de redução das emissões dos gases do efeito estufa e a contribuição de cada país para redução das emissões destes gases no contexto do desenvolvimento sustentável.

Durante a COP 21 - Conferência das Nações Unidas sobre as Mudanças Climáticas de 2015, 195 países aprovaram o acordo de Paris comprometendo-se, a partir da construção de seus próprios compromissos (INDC - Intended Nationally Determined Contributions) e, considerando a viabilidade social e econômica de cada localidade, a contribuir com a redução das emissões dos gases de efeito estufa e limitar o aumento da temperatura nas próximas décadas. Neste contexto, um dos compromissos firmados pelo Brasil é de redução de 43\% das emissões de gases de efeito estufa até 2030 em comparação às emissões verificadas em 2005 considerando, dentre outros, um aumento da participação de bioenergia sustentável na matriz energética do país e a restauração de 12 milhões de hectares de florestas em seu território (MMA, s/d). Na mesma ocasião o estado de São Paulo se 
comprometeu a restaurar 300 mil hectares até o ano de 2020. Deve-se ressaltar, como apontado por Brancalion et al., (2010, pg 456) que o principal objetivo da restauração florestal é o restabelecimento de florestas que sejam capazes de se autoperpetuar; ou seja, florestas ecologicamente viáveis e independentes de intervenções humanas constantes. Ainda de acordo com o autor, as iniciativas de restauração florestal em áreas tropicais visam principalmente ao comprimento da legislação ambiental, o restabelecimento de serviços ecossistêmicos e/ou à proteção de espécies nativas locais.

Apesar da implementação de diversos planos e programas voltados ao desenvolvimento sustentável e à diminuição do desmatamento no estado de São Paulo e no Brasil, o histórico de ocupação territorial do país, voltado à expansão do cultivo de culturas agrícolas diversas, dos centros urbanos e do agronegócio, revela uma realidade de intensa degradação de biomas importantes como a Mata Atlântica. Para Chazdon e Brancalion (2017, p. 10) a restauração na Mata Atlântica é desafiadora, uma vez que mais de 90\% de sua área remanescente ocorrem em propriedades privadas, e todos os custos de restauração devem ser cobertos pelos proprietários rurais.

De acordo com Conti e Furlan (2014, p. 172), as florestas da Mata Atlântica ocupavam originalmente cerca de 1,36 milhão de $\mathrm{km} 2$, sendo que na atualidade a sua área corresponde a aproximadamente $8 \%$ desse total. Tal devastação se deu inicialmente pela substituição para os cultivos de cana-de-açúcar no Nordeste e do café no Sudeste-Sul; e em momentos seguintes para a expansão dos centros urbanos e indústrias, que exigiram a extração de madeiras de extensas áreas (Conti e Furlan, 2014), dentre elas as que compõem a bacia do Rio Paraíba do Sul.

A bacia do Rio Paraíba do Sul se estende pelo território de três estados brasileiros, ocupando uma área de aproximadamente $57.000 \mathrm{~km}^{2}$. Abrange 184 municípios, sendo 39 localizados no Estado de São Paulo, 57 no Estado do Rio de Janeiro e 88 em Minas Gerais (CEIVAP, s/d). Tem recebido 
especial atenção desde o início da crise hídrica na região sudeste do país (iniciada entre os anos 2013 e 2014), por ser responsável pelo abastecimento de pelo menos $80 \%$ da região metropolitana do Rio de Janeiro e por, num futuro próximo, contribuir para o abastecimento da cidade de São Paulo a partir da transposição de parte das suas águas para o sistema Cantareira. Merece destaque ainda por fornecer serviços ambientais e produtos florestais para os dois maiores centros consumidores do país.

Conforme dados de um estudo realizado pelo WRI Brasil apresentado durante o II Encontro de Atores da Restauração Florestal do Vale do Paraíba, em novembro de 2017, aproximadamente 175 mil hectares ocupados atualmente por pastagens estariam economicamente aptos a receber projetos de recuperação com fins econômicos na região do Vale do Paraíba Paulista (PADOVEZI, 2018). No entanto, apesar destes números e da potencialidade de restauração florestal da área correspondente à bacia do Vale do Rio Paraíba do Sul, ainda se faz desconhecida a capacidade de articulação e o preparo da cadeia da restauração florestal em nível regional para enfrentar o desafio da promoção da restauração em larga escala.

Neste contexto, a partir do ano de 2016 foi formado um grupo de diversos representantes desta cadeia, que vão desde coletores de sementes, produtores de mudas e empresas que planejam e executam projetos até as organizações que fomentam a restauração florestal na região do Vale do Paraíba Paulista. Tal grupo tem buscado, dentre outros, a articulação de uma rede para integração dos atores locais e reconhecimento dos integrantes da cadeia produtiva, compreensão do mercado de restauração florestal na região e delineamento de estratégias para melhoria da posição dos atores locais em prol da sustentabilidade do segmento.

$\mathrm{O}$ estudo aqui apresentado integra uma das primeiras iniciativas deste grupo, cujo objetivo foi realizar um diagnóstico preliminar da situação atual buscando identificar os principais desafios para a estruturação da cadeia de restauração florestal do Vale do Paraíba Paulista. 


\section{Material e Métodos}

A metodologia aplicada para elaboração do diagnóstico da situação atual da cadeia de restauração florestal do Vale do Paraíba Paulista pode ser dividida em duas etapas principais de caráter exploratório, que contemplam a identificação, a coleta e análise qualiquantitativa de dados e informações dos diversos segmentos da cadeia e seus principais representantes na região.

A identificação dos principais segmentos da cadeia de restauração florestal do Vale do Paraíba Paulista foi realizada por meio de indicações de especialistas e entrevistas a sujeitos-chave representantes de organizações que desenvolvem atividades ligadas ao setor na região. Para a coleta de dados e informações referentes à estrutura e funcionamento da base da cadeia foram aplicados junto ao grupo dos executores um questionário semiestruturado, como sugerido por Marangoni (2005), composto por 27 questões dissertativas que foram reunidas em três grupos: Sementes, Mudas e Ações de Restauração Florestal. Em síntese, a aplicação dos questionários teve como objetivo identificar informações sobre a diversidade e quantidade de espécies florestais coletadas e cultivadas na região; as dificuldades e necessidades da atividade de coleta de sementes; a variação de custos e dificuldades enfrentadas com as sementes; os volumes de produção, variedade e expectativas de venda de mudas; as limitações, necessidades e temas de interesse para capacitação; a área plantada e municípios abrangidos; e as fontes de recursos e modalidades de contratação para restauração.

As questões sobre sementes foram destinadas aos coletores de sementes e viveiristas, sendo 4 destinadas aos coletores de sementes e 3 a viveiristas. Das 14 questões relacionadas às mudas, 10 foram destinadas a viveiristas, sendo as demais destinadas às empresas e organizações não governamentais da região atuantes no setor. Já as questões sobre ações de 
restauração florestal foram destinadas às empresas e organizações não governamentais atuantes na região do Vale do Paraíba Paulista. Os questionários foram enviados por e-mail para os representantes dos diferentes segmentos após contato telefônico inicial para apresentação do objetivo do estudo. O prazo para envio de respostas foi de 40 dias.

Para complemento destas informações foram coletados ainda outros dados e informações sobre as condições, funcionamento e atuação dos diferentes segmentos ligados à cadeia da restauração florestal do Vale do Paraíba Paulista a partir de apresentações e depoimentos coletados durante um evento promovido pelo Instituto Oikos de Agroecologia e seus parceiros. O I Encontro de Atores da Restauração Florestal do Vale do Paraíba buscou reunir a maioria dos representantes de cada segmento identificado. Todos os dados e informações obtidos foram compilados e analisados para a composição do diagnóstico.

\section{Resultados}

Os diferentes segmentos que compõem a cadeia da restauração florestal foram identificados, nomeados e divididos em dois grupos: o Grupo dos Indutores e o dos Executores. O grupo dos Indutores é formado pelos segmentos responsáveis pelo planejamento, estratégias e financiamento da restauração florestal. Já o grupo dos Executores é composto por todos os segmentos responsáveis pela implantação dos projetos de restauração. Devido ao grande volume de dados e informações coletados para a elaboração desse diagnóstico, neste trabalho serão enfatizados os resultados relacionados ao grupo dos Executores, cujos segmentos em conjunto representam a base da cadeia da restauração florestal no Vale do Paraíba Paulista (Figura 1).

Foram identificados e convidados a participar do processo de diagnóstico da cadeia da restauração florestal do Vale do Paraíba Paulista 
211 representantes de 141 organizações, entre órgãos de governo federal, estadual e municipal (32\%); empresas (26\%); organizações da sociedade civil sem fins lucrativos como organizações não-governamentais (ONG) (18\%); associações, conselhos e redes (13\%); universidades (6\%); e 11 profissionais que atuam de forma independente neste setor (5\%).

Figura 1. Segmentos da Cadeia da Restauração Florestal no Vale do Paraíba Paulista.

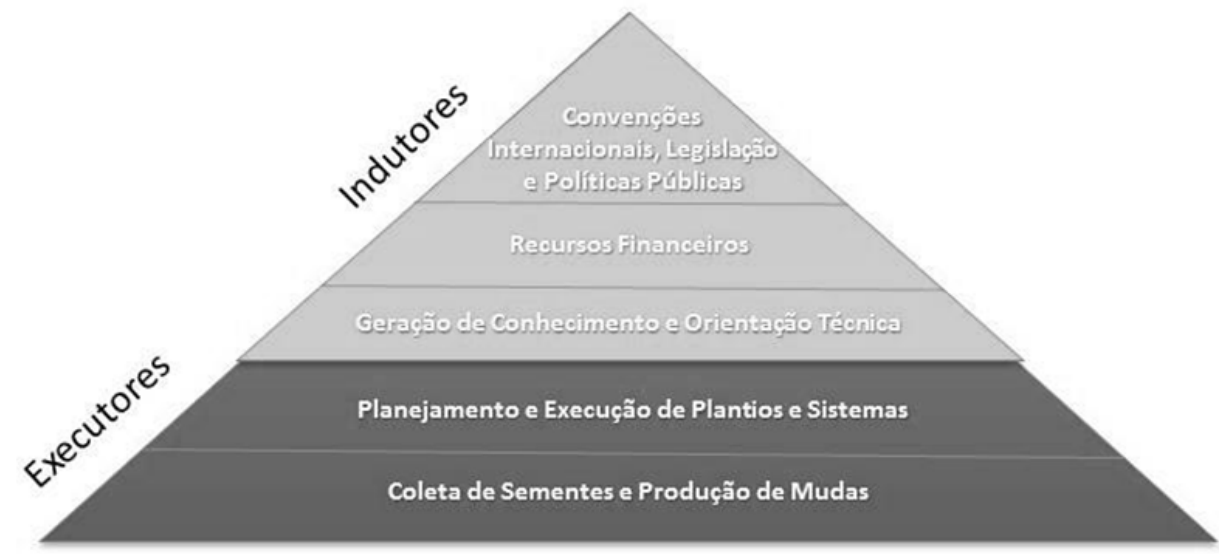

Organização: Org. dos autores, 2018.

Para o levantamento de dados junto ao grupo dos Executores foram convidadas à participação 74 organizações, sendo que destas, 21 responderam ao questionário (28\% dos mobilizados). Das organizações que contribuiram com o preenchimento dos questionários, quatro fizeram também exposições orais no I Encontro dos Atores da Restauração Florestal do Vale do Paraíba, que contou com a participação de 154 pessoas pertencentes a 64 organizações.

Em relação ao grupo dos Executores, os dados coletados indicam que os representantes desse segmento exercem, em sua maioria, mais de uma atividade dentro do grupo e respondem por mais de um segmento na cadeia da restauração; como é o caso, por exemplo, de representantes que se apresentam como coletores e viveiristas, ou daqueles que se apresentam como viveiristas e executores de plantios. Da amostra analisada, 11 
organizações exercem a atividade de planejamento e 11 executam plantios; 10 produzem mudas e 5 realizam coleta de sementes, independentemente de outras atividades desenvolvidas.

Sobre a coleta de sementes, os cinco coletores de sementes que responderam ao questionário afirmaram que o grupo coletou entre os anos de 2014 e 2015 aproximadamente $2.150 \mathrm{~kg}$ de sementes, sendo a riqueza de espécies coletadas muito desigual entre eles (15; 35; 70; 80 e 103 espécies). Já em relação ao custo médio da semente beneficiada os coletores consideram variar conforme a espécie e as condições gerais da coleta, com uma única menção ao valor médio como sendo o valor de $\mathrm{R} \$ 115,00 / \mathrm{kg}$. Já sobre a produção e comercialização de mudas, $80 \%$ dos 10 produtores que contribuíram com a pesquisa relataram preocupações relacionadas aos aspectos e gestão do mercado, tais como captação de clientes, adequação da estrutura à demanda, instabilidade do mercado, profissionalização da atividade, capacitação em gestão e qualificação da mão de obra); $60 \%$ mencionaram a falta de políticas públicas para o setor e à pouca organização da categoria; e 30\% apontaram aspectos relacionados à baixa variedade de espécies disponíveis na região, baixo índice de germinação e elevado custo das sementes. Quanto à origem das sementes, $30 \%$ dos viveiristas participantes da pesquisa relataram adquirir sementes integralmente de fornecedores externos. Outros 30\% afirmaram coletar parte das sementes utilizadas, sendo que apenas um viveirista afirmou que aproximadamente $15 \%$ das sementes utilizadas são adquiridas na base de troca com parceiros regionais. Metade dos viveiristas participantes da pesquisa é considerada de médio porte (100 e 250 mil mudas/ano), 40\% de porte pequeno (até $100 \mathrm{mil}$ mudas/ano) e apenas um foi classificado como de grande porte (mais de 300 mil mudas/ano). Em geral, os viveiros trabalham com um mínimo de 40 espécies de mudas florestais por expedição e um máximo de 110 espécies, com tamanhos de mudas variando entre 0,20 e 6 metros. 
Em relação ao volume de produção é possível projetar, com base nas respostas do grupo de viveiristas participantes da pesquisa (10 viveiristas), uma produção de aproximadamente 1.395 .000 mudas para o ciclo 2016/2017 e 1.560.000 mudas para o ciclo 2017/2018. Considerando o volume de vendas nos período de 2014/2015 e 2015/2016, pode-se notar um aumento de aproximadamente $46,8 \%$ no total de mudas vendidas. Em geral, para 50\% dos viveiristas os principais compradores dessa produção são os proprietários rurais. Para outros 40\%, os principais clientes são as construtoras, portos de areias e mineradoras. Os demais mencionaram ainda as empresas de papel e celulose, empresas de reflorestamento e investidores de madeira. Ainda para os viveiristas foi questionada a necessidade de capacitação no setor. Dos participantes da pesquisa, $70 \%$ consideram importante a capacitação, sendo os principais temas sugeridos: qualificação técnica para produção e manutenção dos viveiros (70\%) e capacitação para gestão e comercialização (29\%).

Buscando a compreensão dos processos de planejamento de execução e plantio e de sistemas foi questionado ao grupo dos executores (empresas e ONG) sobre a procedência, a política de aquisição, e os pareceres sobre a qualidade e diversidade das mudas utilizadas. Neste ponto, vale ressaltar que considera-se como plantio, o plantio em área total (geralmente com espaçamento de $3 \times 2$ ou $2 \times 2$ com uso de espécies pioneiras e não pioneiras e com objetivo de restaurar as funções ecológicas); a regeneração natural (passiva ou assistida), técnicas de adensamento ou enriquecimento, e a nucleação; enquanto sistemas podem envolver técnicas variadas, como consórcio de um número reduzido de espécies (nativas e não nativas) e também os SAF (sistemas agroflorestais). A maioria dos participantes informou que a aquisição das mudas ocorre na própria região, sendo que 20(\%) possuem viveiros próprios. Apenas quatro afirmaram adquirir mudas na região ou fora, havendo uma indicação de aquisição de mudas em outros locais do país em dependência do preço e disponibilidade para garantia da 
diversidade de espécies a serem oferecidas aos seus clientes. Em relação à qualidade das mudas, para a maioria dos que responderam ao questionário (43\%), a qualidade das mudas é considerada variável ou parcialmente boa.

Sobre a área de atuação dos executores pode-se dizer, com base nas respostas de 13 instituições que responderam sobre o tema "área de atuação", que se trata de uma área bastante ampla, não se limitando apenas à região do vale do Paraíba Paulista, apesar de ser esta a área de maior atuação dos executores, com a menção de 51 intervenções de restauração florestal na região no período que compreende os anos de 2014 e 2016. Quanto à fonte de recursos para restauração, a maioria dos entrevistados (64\%) informou receber recursos provenientes de TAC (Termo de Ajustamento de Conduta) e TCRA (Termo de Compromisso de Recuperação Ambiental). Foram citados também os recursos privados e particulares (8), editais públicos e privados (4) e recursos provenientes de doações de pessoas físicas e jurídicas (3).

Por fim, em relação às limitações e necessidades do segmento dos restauradores, foi indicado pela maioria dos executores restauradores (54\%) que a principal limitação do segmento é a falta de mão-de-obra especializada para as atividades de viveiro e plantio de mudas. Para $31 \%$ dos participantes da pesquisa outra limitação refere-se à disponibilidade de áreas e dificuldade de conscientizar e convencer os proprietários rurais sobre os impactos positivos da restauração florestal na propriedade. Houve ainda menções à falta de recursos e editais (23\%) e questões relacionadas às dificuldades impostas pela sazonalidade do trabalho e ao crescente número de incêndios florestais. 


\section{Discussões}

O grupo dos Executores da restauração é formado por dois segmentos da cadeia: Coleta de Sementes e Produção de Mudas (viveiros públicos e privados, e as iniciativas particulares de coleta de sementes e produção de mudas) e Planejamento e Execução de Plantios e Sistemas (empresas, ONGs e proprietários rurais); em geral, os representantes desses segmentos exercem mais de uma atividade dentro do grupo dos executores, buscando dessa forma viabilizar, por exemplo, a oferta de sementes para os viveiros e de mudas para a execução de plantios, além de caracterizar uma estratégia de sobrevivência do setor.

O grupo dos Indutores envolve três outros segmentos da cadeia de restauração: Geração de Conhecimento e Orientação Técnica (órgãos públicos, universidades, ONGs e consultores independentes); Recursos Financeiros (provenientes das compensações ou mitigações ambientais geradas nos processos de licenciamento ambiental; das políticas públicas, como as verbas de cobrança pelo uso da água administradas pelos comitês de bacia [CEIVAP e CBH-PS], e verbas complementares do Fundo Estadual de Recursos Hídricos [também administradas pelo CBH-PS], além dos orçamentos municipais, estaduais e federais determinados por políticas específicas); e Convenções Internacionais, Legislação e Políticas Nacionais.

Para o segmento de coleta de sementes as principais dificuldades estão relacionadas à obtenção de sementes e a aspectos relacionados à gestão da atividade e à variedade, diversidade e qualidade das sementes. Para a maioria dos coletores (80\%), a simples e direta proibição, e/ou a burocracia oficial para autorização de entrada e coleta em Reservas e Parques (Unidades de Conservação) e em propriedades particulares são as principais barreiras ao desenvolvimento de suas atividades. $\mathrm{O}$ acesso à compra e a falta da cultura de troca de sementes entre coletores e viveiristas 
também são considerados barreiras a este processo. Além destas, as questões relacionadas à qualidade genética; a dificuldade para localização e marcação de matrizes, muitas vezes relacionadas às dificuldades para identificação das espécies em campo e ausência de laboratórios; e à baixa variedade de espécies na região também foram identificadas como barreiras para estes segmentos.

Em geral, a alta variação de preços, o elevado custo da mão-de-obra e a falta de conhecimento técnico para produção de mudas constituem as maiores preocupações relacionadas à gestão da atividade dos segmentos representantes do grupo dos Executores na região do Vale do Paraíba Paulista. Ademais, outros desafios encontrados na gestão da produção de mudas florestais estão relacionados à própria desestruturação da cadeia (cujos atores não se encontram plenamente articulados e não se comunicam adequadamente de forma a fortalecer toda a cadeia), a falta de apoio das prefeituras e de incentivos através de programas e projetos governamentais para aquisição de equipamentos e maquinário.

Neste contexto, é importante ressaltar que tais desafios não são exclusivos para a região estudada, configurando-se como uma realidade para as atividades do segmento em todo o país. Como apontado por Silva et al (2014, pg. 95) em seu estudo sobre os desafios da cadeia de restauração florestal para a implementação da Lei Federal 12.651/2012 no Brasil, "a produção de sementes, base da cadeia da restauração florestal, tem alta informalidade e a legislação acaba prejudicando a estruturação desta cadeia"; pois, na verdade, a cadeia produtiva de mudas e sementes no país é deficitária, especialmente a de sementes, onde "há significativos fatores que limitam a sua produção, seja pela legislação atual, seja pela complexidade fenológica inerente às espécies nativas ou pela deficiência logística (da produção em si, da armazenagem e da comercialização)" (DALDEGAN, 2016). Mesmo as instruções normativas mais recentes, como a Instrução Normativa do Ministério da Agricultura, Pecuária e Abastecimento nº 17 de 
26 de abril de 2017, que regulamenta a produção, comercialização e a utilização de sementes e mudas de espécies nativas e exóticas, parece não ter surtido o efeito esperado nos segmentos base da cadeia da restauração florestal no país e na redução da informalidade nos setores de produção de sementes e mudas, apesar de isentar os pequenos produtores a se adequarem a regras rígidas legalmente impostas.

Os atores que compõem o segmento de produção e comercialização de mudas enfrentam praticamente os mesmos desafios impostos aos coletores de sementes. Para a aquisição de mudas, os executores de plantios apontaram como importantes questões relacionadas ao preço, qualidade da muda, procedência geográfica e cumprimento das exigências legais de tamanho e diversidade. Em geral, as preocupações compartilhadas pelos viveiristas concentram-se em sua maioria em aspectos relacionados à gestão e mercado (captação de clientes; adequação da estrutura à demanda; instabilidade do mercado; capacitação em gestão; e qualificação da mão de obra), a ausência de políticas públicas para o setor (morosidade da aplicação das leis ambientais a empresas infratoras e a falta de incentivo para reflorestamento de reserva legal e áreas de preservação permanente) e a pouca organização da categoria. Vale ressaltar ainda a preocupação dos viveiristas com a qualidade das sementes adquiridas, onde é possível constatar, com base nas respostas dos participantes, problemas relacionados à baixa variedade, baixa taxa de germinação e reduzida vida útil das sementes.

Apesar dos desafios, a projeção do volume de produção de mudas para o período de 2014 a 2018 é crescente para a maioria dos entrevistados (Figura 2). Em relação ao período de 2014/2015 e 2016/2017 é possível constatar um aumento de $86 \%$ no volume da produção de mudas, o que demonstra uma expectativa dos produtores relacionada ao possível crescimento da demanda por novas mudas e plantios; demanda essa ainda desconhecida. 
O volume de vendas de mudas florestais no Vale do Paraíba Paulista também apresentou aumento nos últimos anos. De acordo com os dados coletados a partir dos questionários é possível constatar um aumento de aproximadamente $33 \%$ no volume de vendas da produção de mudas entre os períodos de 2014/2015 e 2015/2016 (Figura 3). No período de 2014/2015 foi produzido um excedente de 249.970 mudas, enquanto no período de 2015/2016 o excedente foi 303.459 mudas, correspondendo a 29,8 e 27,9\%, respectivamente.

Esse excedente pode estar associado à qualidade e variedade das mudas produzidas; pois como apontado pela maioria dos representantes do segmento de planejamento e execução de plantios e sistemas que participaram da pesquisa (40\%), a diversidade das mudas é baixa ou limitada, com predominância de espécies de preenchimento (secundárias tolerantes à sombra) em detrimento do oferecimento de espécies pioneiras mais rústicas (de rápido crescimento e resistente a secas); ou ainda, como no restante do país, devido à demanda irregular e instável, resultado da ausência de uma política permanente de apoio ao setor (DALDEGAN, 2016).

Figura 2. Volume e expectativa da produção de mudas florestais na região do Vale do Paraíba Paulista entre os anos de 2014 e 2018.

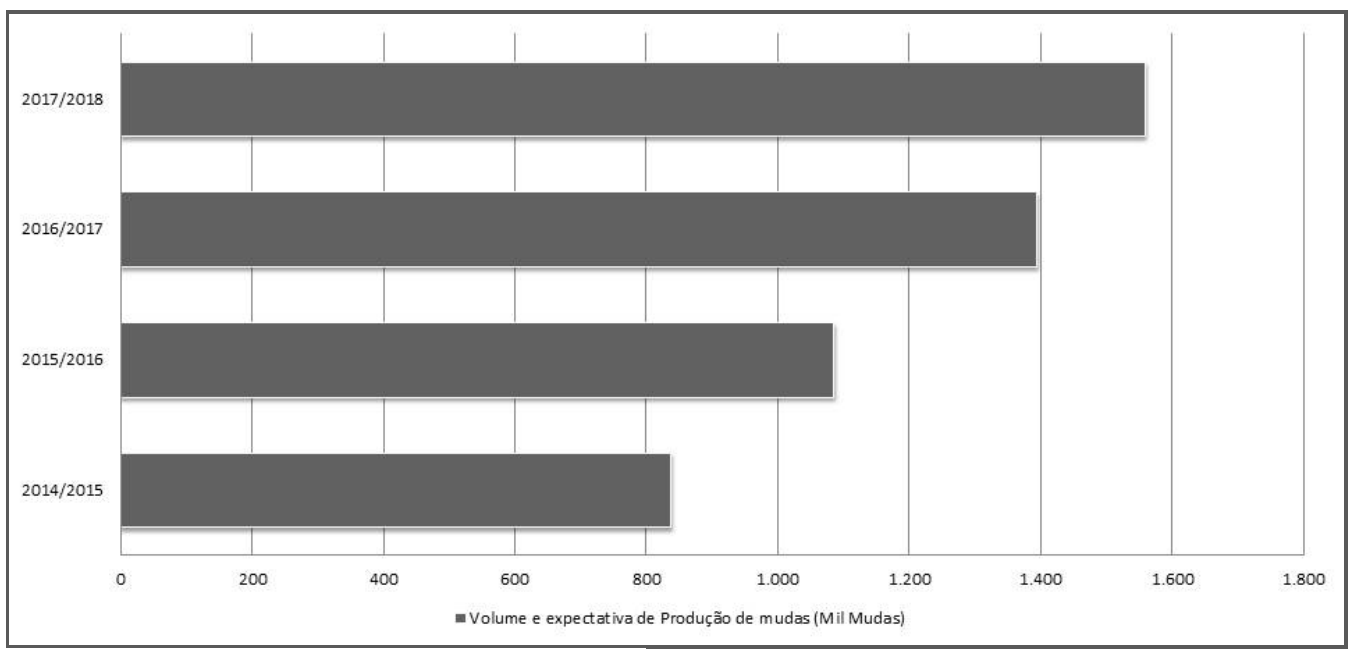

Organização: Org. dos autores, 2018. 
Figura 3. Produção e venda de mudas nos períodos de 2014/2015 e $2015 / 2016$.

Organização: Org. dos autores, 2018.

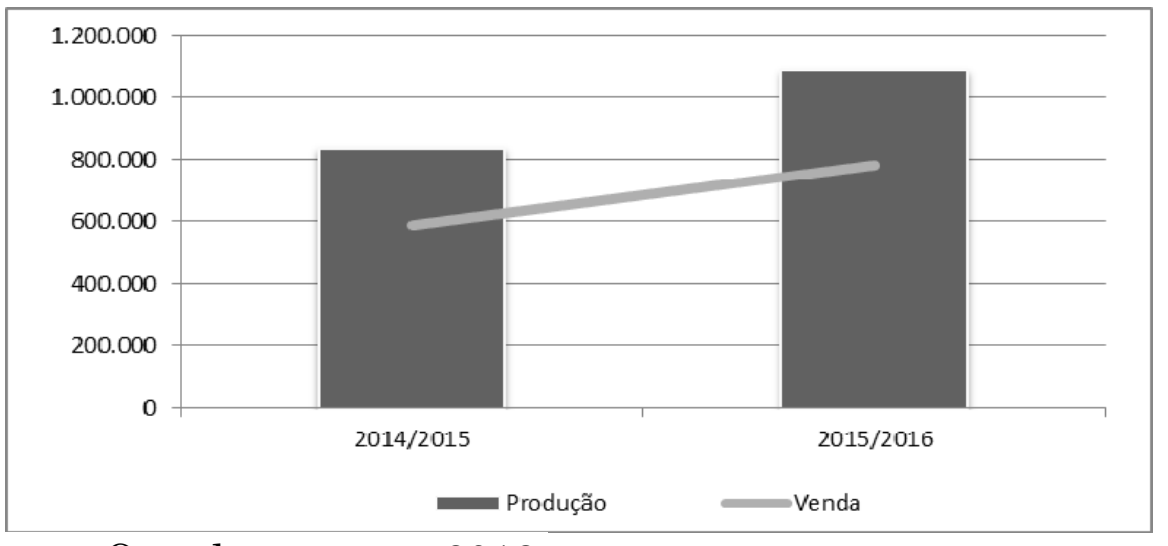

Neste contexto, vale lembrar que grande parte do mercado florestal brasileiro foi estruturado para a produção de espécies exóticas destinadas à monocultura de floresta (SILVA, et al., 2014); o que aparenta não ser uma realidade diferente na região do Vale do Paraíba Paulista que, conforme dados do Estudo de Economia dos Ecossistemas e da Biodiversidade (TEEB) - porção Bacia Hidrográfica Paraíba do Sul/São Paulo, apresentou um significativo aumento da monocultura de eucalipto nos últimos 30 anos. Ainda em relação à disponibilidade das mudas, houve menções à baixa diversidade de espécies para atendimento a demanda de áreas superiores a 10 hectares e à disponibilidade limitada de mudas com porte maior que 0,30 metros.

O levantamento de dados junto aos produtores de mudas evidenciou claramente a necessidade de maior profissionalização do setor e qualificação técnica para produção e manutenção de viveiros, considerando praticamente todos os aspectos técnicos e de gestão e comercialização da produção: insumos, produção de substrato e adubação, quebra de dormência, germinação, identificação e coleta de sementes, multiplicação de espécies, rustificação, transplante, controle de pragas e doenças, manuseio e irrigação; além da capacitação para gestão e comercialização que envolve a montagem e instalação de viveiros, planejamento de estoque, expedição, 
definição de custo e preço de venda, empreendedorismo e marketing, e aspectos legais da atividade.

Nesta perspectiva, ganha importância a atuação das universidades e centros de pesquisa no desenvolvimento de novas pesquisas, difusão do conhecimento e assistência técnica para fortalecimento da cadeia. Em escala nacional, Silva et al., (2014, pg 95) identificaram que "a assistência técnica destinada a espécies florestais nativas ainda não é uma realidade entre os produtores de sementes e mudas, ou mesmo na pequena propriedade", pois quando há, esta é destinada a atividades florestais com o cultivo comercial consolidado. No caso da região do Vale do Paraíba Paulista, ganha destaque o Polo Regional do Vale do Paraíba da APTA - Agência Paulista de Tecnologia de Agronegócios, que tem alcançado a liderança na geração de conhecimento sobre o funcionamento dos SAFs e na orientação técnica aos proprietários rurais. Já grande parte das instituições de ensino e pesquisa presentes na região, apesar do potencial técnico identificado, não possui ainda uma tradição na geração de conhecimento sobre os temais florestais e agronômicos voltados para a conservação de ecossistemas e a restauração de paisagens, sendo identificadas apenas algumas iniciativas em curso.

As fontes de recursos financeiros para restauração também foram evidenciadas pelos restauradores, reforçando a dependência entre grupos e segmentos da cadeia da restauração florestal do Vale do Paraíba Paulista. Para a maioria dos participantes da pesquisa os recursos utilizados são provenientes de compensações ambientais, TAC, TCRA e condicionantes ambientais de licenciamentos, seguidos do que foi identificado como recursos privados. Vale lembrar, como informado por representantes de ONG, que nem todas as instituições e/ou organizações tâm acesso aos mesmos recursos, pois há organizações que somente acessam recursos financeiros por meio de editais públicos e que, na prática, existem restrições nesses documentos para que essas instituições e/ou organizações executem TACs e TCRAs. Assim, o elevado preço dos insumos e mudas, a alta carga 
tributária, a escassez de fontes de recursos e de políticas publicas efetivamente implantadas na região acabam comprometendo o retorno financeiro da atividade e dificultando a organização da cadeia da restauração florestal.

De acordo com as informações coletadas junto a representantes de diferentes segmentos e durante o I Encontro de Atores da Restauração Florestal do Vale do Paraíba, a recente história da restauração florestal na região indica que políticas públicas que envolvem um ou mais segmentos da cadeia foram implantadas na região em caráter piloto, com reduzido incentivo à expansão de suas atividades e continuidade. Por outro lado, é possível identificar a destinação de recursos financeiros específicos para restauração florestal oriundos das politicas de recursos hídricos implantadas pelos Comitês de Bacias (CBH-PS e CEIVAP). A revisão do Plano da Bacia do Paraíba do Sul - trecho paulista, realizada em 2016, destinou 20\% dos recursos do comitê para implantação de ações de restauração florestal nas bacias de mananciais públicos da região. No âmbito do Comitê de Integração da Bacia Hidrográfica do Rio Paraíba do Sul (CEIVAP), o programa de pagamentos por serviços ambientais - PSA Hídrico está em sua segunda fase (2017-2020) com a aplicação de novos recursos e aporte financeiro para o desenvolvimento do programa e consequentemente para as atividades que envolvem os diferentes segmentos da cadeia da restauração florestal na região.

\section{Considerações Finais}

O levantamento de dados e informações dos principais segmentos que compõem a cadeia de restauração florestal do Vale do Paraíba Paulista foi fundamental para a compreensão da organização e da estrutura de cada grupo, Indutores e Executores da restauração florestal. Embora não tenha sido possível mobilizar todos os agentes contatados para participação na 
pesquisa, considera-se que os resultados encontrados são suficientes para compreensão, mesmo que preliminar, da atual situação e demandas da cadeia na região estudada.

Os resultados deste diagnóstico sinalizam a necessidade de uma melhor articulação e comunicação entre os diferentes segmentos que compõem a cadeia da restauração florestal do Vale do Paraíba Paulista como um todo, e também entre os segmentos de um mesmo grupo, sendo este o caso dos Executores das atividades de restauração, considerados a base da cadeia (produtores de sementes e mudas florestais e organizações que planejam e executam os plantios e manutenções), que enfrenta adicionalmente grandes desafios, comuns a outras regiões do país, que vão desde o acesso às sementes florestais e áreas para restaurar até a dificuldade no acesso aos recursos financeiros existentes e a carência de conhecimento e capacitação técnica no exercício das atividades.

A partir dos dados e informações coletados, pode-se concluir que as demandas de compensações e compromissos de restauração (TAC e TCRA) na região não estão disponíveis publicamente, impossibilitando à base da cadeia se programar para a produção, ou tornando o planejamento da produção de mudas e sementes baseado em expectativas e incertezas relacionadas ao cumprimento das obrigações legais ou a programas e projetos públicos anunciados, que normalmente têm seus prazos prorrogados ou que não são executados por falta de fiscalização.

A falta de uma demanda firme para aquisição de mudas e sementes, com contratos estabelecidos, inviabiliza o planejamento adequado da produção de sementes e mudas florestais nativas, acarretando prejuízos financeiros graves e mesmo o fechamento de viveiros consolidados nos últimos anos, como constatado pelo estudo. Soma-se a este cenário a dificuldade de identificação das áreas privadas disponíveis para restauração, problema recorrente enfrentado pelo segmento da base da cadeia, empresas e organizações de planejamento e execução de plantios. Essa dificuldade 
poderia ser amenizada a partir de iniciativas como o Banco Público de Áreas para Restauração (BANPAR-INEA/RJ) que mantém um cadastro de áreas disponíveis para a restauração florestal no Estado do Rio de Janeiro e facilita a aproximação entre os proprietários de áreas a serem restauradas e aqueles que buscam essas áreas para cumprir, dentre outros, compromissos ambientais de restauração florestal, compensão ambiental e de emissões de GEE.

A soma desses fatores caracteriza a precariedade da economia florestal hoje estabelecida na região do Vale do Paraíba Paulista, com exceção da produção florestal para geração de celulose, que teve expansão significativa na região a partir da década de 2000 (DEVIDE et al, 2014).Assim, torna-se evidente a necessidade da construção de políticas públicas duradouras, regionalizadas, com envolvimento e participação permanente do governo estadual, para a restauração das paisagens regionais com objetivo de conservação da biodiversidade e de produção florestal nativa com fins econômicos. Isso trará como consequência: a estruturação e movimentação da economia florestal local/regional; a viabilidade econômica e o planejamento da produção de sementes e mudas florestais. Permitirá também o atendimento às normas e legislação vigentes para o exercício das atividades, hoje dificultadas pelas exigências técnicas e pelos elevados custos financeiros.

Algumas iniciativas estão sendo gestadas por parte de representantes do Grupo dos Indutores da restauração, responsáveis pelo planejamento, financiamento, geração de conhecimento e criação de políticas públicas. São exemplos disso o Plano de Desenvolvimento Florestal Territorial, desenvolvido pelo WRI Brasil, que mapeou vocações, oportunidades, melhores métodos e custos para restauração das paisagens regionais; a demanda recentemente criada pelo Comitê Paulista da bacia do Rio Paraíba do Sul CBH-PS com destinação de investimentos anuais para restauração das áreas de mananciais de abastecimento público; o Programa Nascentes e 
o Polo Florestal de Usos Múltiplos, fomentado pela Secretaria de Meio Ambiente do Estado de São Paulo. Espera-se que essas iniciativas contribuam para a estruturação da base da cadeia da restauração florestal do Vale do Paraíba Paulista e, consequentemente, para a criação de uma nova economia florestal regional.

Considera-se que já foram dados os primeiros passos no sentido de promover o fortalecimento e a articulação da cadeia, através da criação de uma rede intitulada "Atores da Restauração Florestal do Vale do Paraíba", que congrega os diversos segmentos da cadeia - Executores e Indutores da restauração, e que tem como objetivo maior contribuir para o estabelecimento de uma efetiva economia florestal na região, a partir da articulação entre os diversos agentes do segmento, a participação na construção de políticas públicas para o setor e a disseminação de informações de interesse da cadeia. Dentre as principais atividades desenvolvidas pela rede de atores da restauração florestal do Vale do Paraíba destaca-se a organização de dois encontros regionais $(2016,2017)$ que somaram mais de 300 participantes e a criação de uma rede de e-mail com 170 representantes dos grupos dos Executores e Indutores da restauração florestal do Vale do Paraíba Paulista. Com a continuidade dessa iniciativa espera-se preparar o segmento da restauração florestal para as demandas de geração de bens e serviços ecossistêmicos, necessários ao cumprimento dos compromissos assumidos pelo Brasil frente às Conferencias Internacionais de Clima e Biodiversidade.

\section{Referências}

BRANCALION, P.F.S.; RODRIGUES, R.R.; GANDOLFI, S; KAGEYAMA, P.Y.; NAVE, A.G.; GANDARA, F.B.; BERTIN, F.; BARBOSA, L.M.; TABARELLI, M. Instrumentos legais podem contribuir para a restauração de florestas tropicais biodiversas. Revista Árvore, Viçosa-MG, v.34, n.3, p.455-470, 2010.

BRASIL. Ministério do Meio Ambiente. Disponível em: http://www.mma.gov.br/clima/convencao-das-nacoes-unidas/acordo-de-paris. Acesso em: 16 jan. 2018 . 
CEIVAP. Dados Gerais. Disponível em: http://www.ceivap.org.br/dados-gerais.php. Acesso em: 30 nov. 2017.

CHAZDON, R.L.; BRANCALION, P.H.S. Priorização da regeneração natural para melhorar o custo-efetividade da restauração florestal na mata atlântica do Brasil. In: Anais do VII Simpósio de Restauração Ecológica, 2017. Disponível em: http://www3.ambiente.sp.gov.br/institutodebotanica/files/2017/11/Anais_PDF_Vers\% C3\%A3o-31_X_2017_com-ISBN.pdf. Acessado em: 20 dez. 2017.

CONTI, J.B.; FURLAN, S.A. Geoecologia: o clima, os solos e a Biota. In: ROSS, J.L. (org). Geografia do Brasil. São Paulo: Edusp, 2014.

DALDEGAN, J.S. Subsídios à elaboração de uma política pública para contribuir na estruturação da cadeia da restauração florestal: o programa de aquisição de sementes e mudas nativas (PASEM). In: SILVA, A.P.M., MARQUES, H.R., SAMBUICHI, R.H.R., ROSA, R.H. Mudanças no código florestal brasileiro: desafios para a implementação da nova lei. Rio de Janeiro: Ipea, 2016.

DEVIDE, A.C.P.; CASTRO, C.M. de; RIBEIRO, R.L.D.; ABBOUD, A.C.S.; PEREIRA, M.G.; RUMJANEK, N.G. História Ambiental do Vale do Paraíba Paulista, Brasil. Revista Biociências (Taubaté), v. 20, p. 120-290, 2014.

MARANGONI, A.M.M.C. Questionários e entrevistas. Algumas considerações. In: VENTURI, L.A.B. Praticando Geografia: técnicas de campo e laboratório. São Paulo. Oficina de Textos, 2005.

PADOVEZI, A. (coord.) Oportunidades para restauração de paisagens e florestas na porção paulista do Vale do Paraíba: Plano de Desenvolvimento Florestal Territorial para a porção paulista do Vale do Paraíba. Porto Alegre: Ideograf, 2018.

SEEG/Observatório do Clima. Evolução das emissões de gases de efeito estufa no Brasil (1970-2013): setor agropecuário. Instituto de Manejo e Certificação Florestal e Agrícola (IMAFLORA). São Paulo, 2015. 57 p.

SILVA, A.P.M.; MARQUES, H.R.; LUCIANO, M.S.F.; SANTOS, T.V.M.N.; TEIXEIRA, A.M.C.; SAMBUICHI, R.H.R. Desafios da cadeia de restauração florestal para a implementação da lei no 12.651/2012 no Brasil. In: MONASTERIO, L.M.; NERI; M.C.; SOARES, S.S.D. (editores) Brasil em desenvolvimento 2014: estado, planejamento e políticas públicas. Brasília: Ipea, v.2, 2014. 